\title{
Religiousness and Mental Health Reconsidered: A Study of an Intrinsically Religious Sample
}

\author{
Allen E. Bergin \\ Brigham Young University - Provo \\ Kevin S. Masters \\ Brigham Young University - Provo \\ P. Scott Richards \\ Brigham Young University - Provo, scott_richards@byu.edu
}

Follow this and additional works at: https://scholarsarchive.byu.edu/facpub

Part of the Student Counseling and Personnel Services Commons

\section{Original Publication Citation}

Bergin, A.E., Masters, K.S., \& Richards, P.S. (1987). Religiousness and mental health reconsidered: A study of an intrinsically religious sample. Journal of Counseling Psychology, 34, 197-204.

\section{BYU ScholarsArchive Citation}

Bergin, Allen E.; Masters, Kevin S.; and Richards, P. Scott, "Religiousness and Mental Health Reconsidered: A Study of an Intrinsically Religious Sample" (1987). Faculty Publications. 3870.

https://scholarsarchive.byu.edu/facpub/3870

This Peer-Reviewed Article is brought to you for free and open access by BYU ScholarsArchive. It has been accepted for inclusion in Faculty Publications by an authorized administrator of BYU ScholarsArchive. For more information, please contact ellen_amatangelo@byu.edu. 


\title{
Religiousness and Mental Health Reconsidered: A Study of an Intrinsically Religious Sample
}

\author{
Allen E. Bergin and Kevin S. Masters \\ Brigham Young University \\ P. Scott Richards \\ University of Minnesota
}

\begin{abstract}
Despite the existence of strong viewpoints, the relation between religiousness and mental health is not yet clearly understood. The Religious Orientation Scale has provided researchers with a valuable tool for differentiating between intrinsic $(I)$ and extrinsic $(E)$ religious orientations, thereby clarifying some of the confusion in this area. In the present study we assessed correlations between these two scales and anxiety, personality traits, self-control, irrational beliefs, and depression. Results generally indicated that $I$ is negatively correlated with anxiety and positively correlated with self-control and "better" personality functioning, whereas the opposite is true of $E$. Correlations were generally not found with irrational beliefs or depression. By dividing subjects into a fourfold typology, we discovered that $98.6 \%$ of the present sample of religious students were "intrinsics." When their personality scores werè compared with those of other normal populations, trends slightly favoring this intrinsic sample were observed. Thus, these results indicated that $I$ is related to "normality" and that religiousness is not necessarily indicative of emotional disturbance. Some implications for counseling are suggested.
\end{abstract}

A few years ago, a debate occurred concerning psychotherapy, religious values, and mental health (Bergin, 1980a, 1980b; Ellis, 1980; Walls, 1980). The main issues follow: (a) Do values permeate therapeutic change processes and the evaluation of outcomes? (b) Are the values of counselors and therapists generally discrepant from those of the public at large, especially the majority who profess traditional theistic beliefs? (c) Do professionals convey personal ideologies and reinforce acceptance of them by clients? (d) Is there, thus, an implicit mental health value system that has mainly humanistic and naturalistic bases? (e) Is religiousness generally healthy or unhealthy as viewed from the values perspective of mental health professionals?

More commentaries were submitted on these matters than could be published, but exchanges continued by means of professional meetings, colloquiums at universities here and abroad, articles in other journals, and correspondence among interested people. In addition to these continuing interactions, we received more than 1,000 requests for reprints, many of which included commentaries on the main issues. Considering the thousands of exchanges that we have had since 1980 , we believe there is a consensus on Items a through d, with the predominant answer being yes. Item e, however, remains controversial.

Portions of this article were presented in the symposium Spiritual Issues: Do They Belong in Psychological Practice? at the American Psychological Association annual convention in Los Angeles in August 1985.

We thank Tom Gaskin and Michael Donahue for their valued assistance on this project.

Correspondence concerning this article should be addressed to Allen E. Bergin, Kimball Tower, Box 72, Brigham Young University, Provo, Utah 84602.
We were not surprised by the reactions to the five issues, but there were two unexpected developments. First, there was an outpouring of support for theistic perspectives by a number of colleagues. Second, despite a diversity of opinions on theistic matters, there was an unusual degree of agreement regarding the kinds of personal and social values that professionals consider healthy. The importance of these matters was reflected in part by the number of significant contributors to the field who became involved. Those with whom we have conversed or corresponded on these matters include Albert Bandura, Ellen Berscheid, Larry Beutler, Robert Coles, Richard Jessor, Karl Menninger, Carl Rogers, Robert Sears, Hans Strupp, and Paul Vitz.

A recent article with commentaries and a reply provides quotations from a number of these individuals and a summary of the values that many of them endorse (Bergin, 1985a, 1985b, Gazda, 1985; Sprinthall, 1985). These values were summarized under the following seven headings: (a) Autonomy, (b) Nurturant Relationships, (c) Identity, (d) Goal Direction, (e) Integrity, (f) Work, and (g) Symptom Control.

A national survey was recently conducted for determining how widespread agreement is among mental health professionals concerning these and a number of other values. Preliminary analyses support the notion that a substantial majority endorse various values as mentally healthy. Disagreement continues, however, over the value of theistic versus nontheistic orientations (Jensen, 1986).

In the light of the foregoing, we have been pursuing several continuing lines of inquiry: One is to describe, measure, and study the correlates of values that may be characteristic of mentally healthy life-styles (Bergin, Stinchfield, Gaskin, Masters, \& Sullivan, in press); another is to examine the relation of specifically religious values to a variety of personality characteristics and indexes of pathology. The latter is the 
focus of the present report. In it, we consider the possibility that both critics and advocates of religion may be correct; that is, there may be both positive and negative ways of being religious. A third pursuit concerns the implications of these inquiries for counseling and psychotherapy (Bergin, 1985a) and personality theory (Bergin, in press). Unraveling the relation among values, religiousness, personality, mental health, and change processes is a complex and enduring task. Here we consider one slice of the problem and examine possible implications for both theory and practice.

A promising way of distinguishing positive from negative features of religiousness consists of differentiating between intrinsic $(I)$ and extrinsic $(E)$ orientations. This was first suggested by Allport and Ross (1967) when they attempted to clarify the confusing and seemingly contradictory research results regarding religiousness and prejudice. They suggested that extrinsically motivated people use their religion as a means of obtaining status, security, self-justification, and sociability. The extrinsic approach to religion is basically utilitarian. Intrinsic people, on the other hand, internalize beliefs and live by them regardless of the external consequences. Thus, the Religious Orientation Scale (ROS), developed by Allport and Ross, differentiates between those who use religion as a means $(E)$ and those who view it as an end $(I)$. Since their initial research, several investigators have used the $I$ and $E$ dimensions to address questions regarding their relation to personality functioning (Baker \& Gorsuch, 1982; Bolt, 1977; Kahoe, 1974). Donahue (1985) provided a comprehensive review and meta-analysis of this research and concluded that the $I-E$ framework is a useful tool in the assessment of religiousness.

This line of inquiry provides fertile hypotheses that could resolve some of the controversy over the relation of religiousness to mental health. Propositions regarding the issue are abundant and conflicting. Ellis (1980) advocated the view that devout religiousness is indicative of mental and emotional disturbance. An alternative viewpoint was provided by Bergin (1980a), who argued that religiousness can have a variety of positive consequences. On the basis of a reconceptualization (Bergin, 1980b) and meta-analysis of 24 empirical studies (Bergin, 1983), religiousness was shown to be a complex phenomenon that is not consistently correlated with either mental health or illness but to have some health-enhancing aspects and some pathogenic ones.

Because of the interesting possibilities of the ROS, we chose to further investigate the relations between it and several important personality variables-anxiety, self-control, irrational beliefs, depression, and the personality traits measured by the California Psychological Inventory (CPI) (Gough, 1975). Because of previous findings, we expected $I$ to correlate positively and $E$ to correlate negatively with better functioning.

We also used the ROS to classify subjects into a fourfold (2 $\times 2$ ) typology based on scores on the two scales. Allport and Ross (1967) first discussed this procedure, and Hood (1978) developed the current method of classifying subjects into the groups intrinsic (high intrinsic score and low extrinsic score), extrinsic (high extrinsic score and low intrinsic score), indiscriminately proreligious (high on both scales), and indiscrim- inately anti(non)religious (low on both scales). Donahue (1985) suggested that this may be the preferred method of analysis, leading to more precise results, especially when the dependent measure is nonreligious. In general, he concluded that the research using this method produces, with nonreligious dependent variables, findings resulting in the intrinsic and nonreligious groups' scoring "better" than the extrinsics, who score "better" than the indiscriminately proreligious. Thus, the second purpose of this study was to classify students according to the fourfold procedure and to see whether personality traits varied according to type of religiousness.

Because the Mormon students involved in this study adhered to an honor code containing numerous ethical, moral, and behavioral guidelines (including abstinence from alcohol, tobacco, illegal drugs, and sexual relations outside of marriage) and because they tended to be active in religious activity and orthodox in belief, we thought that they would provide a good test of the notions concerning whether religiousness is healthy or unhealthy.

It also seemed that descriptive information on such a religious student sample could be useful to contemporary counselors and therapists, who are more often encountering students and other clients whose lives involve religious themes (Lovinger, 1984; Spero, 1985).

\section{Method}

\section{Subjects}

Between October 1981 and June 1983, Brigham Young University (BYU) juniors and seniors were administered various personality measures during psychology of personality classes that we taught. A total of 119 completed the ROS. Of these 119,78 completed the CPI, 61 completed the Taylor Manifest Anxiety Scale (MAS; Taylor, 1953), and 33 completed Rosenbaum's Self-Control Schedule (SCS; Rosenbaum, 1980). Differing combinations of tests were used from class to class, depending on the interests and purposes of the instructors; consequently, the sample sizes varied across instruments. Some took two tests, some took three, and some took all four.

After these data were collected, we had an opportunity for a further test of the questions that interested us. We were able, in 1985, to assess a religion class composed of $\mathbf{3 2}$ former missionaries (mostly sophomores). We chose to administer the ROS, the Beck Depression Inventory (BDI), and Jones's (1977) standardized measure of Ellis's Irrational Beliefs Test (IBT). We felt that this additional sample and these additional inventories would help extend and elaborate on the findings based on the psychology students and the other instruments.

\section{Procedure}

Subjects were recruited from the courses and informed that the general purpose of the study was to learn more about religiousness and personality. This topic, of course, was not discussed in classes until after the administration of the tests. The tests were given at the end of specific class sessions, except for the CPI, which was administered by appointment at the University Counseling Center. No course credit was offered, and participation was voluntary; students were permitted, however, to use test results in writing their class papers, which increased the incentive to participate. Mote than $75 \%$ of the class enrollees elected to participate. 


\section{Instruments}

Characteristics of the ROS have already been mentioned. Because they are commonly used, we do not report any psychometric data here for the CPI, MAS, and BDI. The SCS was also used and is an experimental instrument that was developed to "assess the tendencies of individuals to apply self-management methods to the solution of common behavioral problems" (Rosenbaum. 1980, p. 110). In this same article, Rosenbaum reported a test-retest reliability (over 4 weeks) of .86 and internal consistency reliabilities ranging from .78 to .84 . In addition, preliminary evidence supporting the construct validity of the SCS has been reported (e.g., Redden, Tucker, \& Young, 1983; Richards, 1985a; Rosenbaum, 1980).

The IBT was designed to measurc irrational beliefs, which are purported to be an index of neurosis or disturbance, as posited by Ellis (Jones, 1977, p. 1). Test-retest reliability for the entire scale has been demonstrated at .92 . and the reliability coefficients for the individual scales range from 68 to .87 . Additionally, the test manual provides evidence of construct validity.

\section{Analyses}

The main analyses were performed on the combined data of the separate psychology classes, but the religion class was analyzed separately. Combining was appropriate because the different psychology classes had virtually identical means and standard deviations on the measures. ROS scores were computed so that for both scales, higher scores indicated a greater degree of that orientation. Pearson correlations were computed for determining the relations of $I$ and $E$ with the MAS, SCS, IBT, BDI, and CPI scales.

Subjects were also classified on the ROS according to the fourfold typology through the use of median splits. The theoretical midpoints of each scale ( 27 for $I$ and 33 for $E$ ) served as the bases for division of the sample. This procedure was suggested by Donahue (1985) as the best way to ensure uniformity among various researchers who use this scale with diverse populations. An alternative possibility of dividing the sample according to observed rather than theoretical medians was considered. For the present sample, however, this procedure tended to grossly distort the meaning of the classifications, so we dropped the idea.

\section{Results}

Table 1 contains obtained correlations of the ROS scales with the MAS, SCS, and CPI for the psychology class and of the ROS with the IBT and BDI for the religion class. The most striking result was the consistent trend of correlations, with $I$ varying with positive personality scores and $E$ showing the opposite trend in the psychology class samples. Results were as predicted on the MAS and the SCS, with higher I scores being associated with lower anxiety and better selfcontrol. Across the CPI, I correlated positively with all scales, nine of which reached accepted levels of statistical significance. On the other hand, $E$ correlated negatively with all but two of these scales. The 2 positive correlations failed to reach statistical significance, but 10 of the negative correlations were significant.

Analysis of responses for the religion class yiclded only two significant correlations with the IBT and no significant correlations with the $\mathrm{BDI}$. The $E$ scale correlated positively ( $r=$ $.36, p<.05$ ) with Scale 5 of the IBT, that is, the belief that human unhappiness is externally caused and that people have
Table 1

Pearson Correlations of the Religious Orientation Scale With the Manifest Anxiety Scale, Self-Control Schedule, California Psychological Inventory, Irrational Beliefs Test, and Beck Depression Inventory

\begin{tabular}{|c|c|c|}
\hline Personality scale & $I$ & $E$ \\
\hline \multicolumn{3}{|c|}{ Psychology classes } \\
\hline $\begin{array}{l}\text { Manifest Anxiety Scale }(n=61) \\
\text { Self-Control Schedule }(n=33) \\
\text { California Psychological Inven- } \\
\quad \text { tory }(n=78) \\
\text { Dominance } \\
\text { Capacity for Status } \\
\text { Sociability } \\
\text { Social Presence } \\
\text { Self-Acceptance } \\
\text { Sense of Well-Being } \\
\text { Responsibility } \\
\text { Socialization } \\
\text { Self-Control } \\
\text { Tolerance } \\
\text { Good Impression } \\
\text { Communality } \\
\text { Achievement by Conformance } \\
\text { Achievement by Independence } \\
\text { Intellectual Efficiency } \\
\text { Psychological-Mindedness } \\
\text { Flexibility } \\
\text { Femininity }\end{array}$ & $\begin{array}{l}.16 \\
.13 \\
.30^{* * *} \\
.07 \\
.03 \\
.34^{* * *} \\
.44^{* * *} \\
.24^{*} \\
.32^{* * *} \\
.35^{* * *} \\
.34^{* * *} \\
.03 \\
.34^{* * *} \\
.17^{* *} \\
.29^{* * *} \\
.17 \\
.06 \\
.08 \\
\end{array}$ & $\begin{array}{l}-.11 \\
-.19^{*} \\
-.21^{*} \\
-.21^{*} \\
-.03 \\
-.24^{* *} \\
-.23^{*} \\
-.08 \\
-.13 \\
-.24^{*} \\
-.26^{* *} \\
.04 \\
-.22^{*} \\
-.23^{*} \\
-.38^{* *} \\
-.17 \\
-.14 \\
.12 \\
\end{array}$ \\
\hline Religion cla & & \\
\hline $\begin{array}{l}\text { Irrational Beliefs Test }(N=32) \\
\text { Total score } \\
\text { Subscales } \\
\text { 1. Approval need } \\
\text { 2. Competency need } \\
\text { 3. Blameworthiness } \\
\text { 4. Catastrophizing } \\
\text { 5. Externalizing } \\
\text { 6. Obsessing } \\
\text { 7. Avoidance } \\
\text { 8. Dependency } \\
\text { 9. Determinism } \\
\text { 10. Perfectionism } \\
\text { Beck Depression Inventory }(N= \\
\text { 32) }\end{array}$ & $\begin{array}{r}-.03 \\
.03 \\
-.07 \\
.16 \\
-.07 \\
-.17 \\
-.02 \\
-.08 \\
.20 \\
-.37 * \\
.23 \\
.05\end{array}$ & $\begin{array}{r}.15 \\
-.04 \\
.16 \\
-.02 \\
-.10 \\
.36^{*} \\
.14 \\
.07 \\
.02 \\
.20 \\
.08 \\
-.02\end{array}$ \\
\hline
\end{tabular}

- Names are our abbreviations.

${ }^{*} p \leq .05{ }^{* *} p \leq .01$. $^{* * *} p \leq .005$.

little or no ability to control their sorrows and disturbances. The $I$ scale correlated negatively $(r=-.37, p<.05)$ with Scale 9 of the IBT. This scale measures the idea that one's history is an all-important determiner of one's present behavior and that because something once strongly affected one's life, it should indefinitely have similar effects. Neither $I(r=$ $.05, p=.38)$ nor $E(r=-.02, p=.46)$ correlated significantly with the BDI.

Generally, we assumed that the magnitude of the reported correlations was underestimated due to the restricted range of . scores on the $I$ and $E$ subscales from the ROS. This was especially true for the former missionary group in the religion class.

Classification of the sample into the fourfold typology according to the procedure suggested by Donahue (1985) 
revealed that 149 of the sample of $151(98.6 \%)$ could be considered intrinsic. One person was extrinsic, and one was anti(non)religious. Because our sample fell almost entirely into one of the four possible cells in the typology, we were forced to drop the idea of pursuing analyses based on this approach.

The means for this and comparative samples from other studies on the ROS scales are depicted in Table 2. Inspection of this table reveals that the present sample exhibited a rather high mean for $I$ and a correspondingly low mean for $E$. From this and the typology information, we had to judge our sample as obviously skewed in the intrinsic direction. Although this allowed for examining the nature of such a group, it also limited our analysis of the extrinsic orientation and of comparisons between the two. The correlations we obtained were based on distributions of scores in the middle to-high range for $I$ and the middle-to-low range for $E$, with low $I$ and high $E$ virtually unrepresented. Our descriptions and inferences, therefore, apply mainly to highly intrinsic people and to the fact that the relation between the $J$ and $E$ distributions is inverse and significant even for this restricted range of scores.

Means and standard deviations for the other measures are presented in Tables 3 and 4 . These are within normal ranges, with a trend for the psychology sample as a whole to have somewhat positive elevations on a number of CPI scales. There were also low scores on the IBT and the BDI relative to normative data for the missionary group.

\section{Discussion}

For both counselors and theorists, our data provide evidence, consistent with other findings (Bergin, 1983; Donahue \& Bergin, 1986), that significant religious involvement can be a positive correlate of normal personal functioning. The scores we obtained for this religiously oriented group were comparable in a positive way with other college and norm groups on nearly every measure used.

Religiousness is, therefore, not necessarily a defect to be analyzed or modified. Although there are cases in which
Table 3

Means and Standard Deviations on the Manifest Anxiety

Scale, Self-Control Scale, and California

Psychological Inventory (for the Psychology Classes)

\begin{tabular}{lccr}
\multicolumn{1}{c}{ Scale } & $N$ & $M$ & \multicolumn{1}{c}{$S D$} \\
\hline Manifest Anxiety Scale & 61 & 15.10 & 7.66 \\
Self-Control Schedule & 33 & 41.80 & 16.50 \\
California Psychological Inventory & & & \\
Dominance & 78 & 58.18 & 10.69 \\
Capacity for Stress & 78 & 51.03 & 10.67 \\
Sociability & 78 & 53.97 & 9.56 \\
Social Presence & 78 & 54.73 & 9.41 \\
Self-Acceptance & 78 & 60.06 & 9.89 \\
Sense of Well-Being & 78 & 46.63 & 10.56 \\
Responsibility & 78 & 46.56 & 8.66 \\
Socialization & 78 & 50.51 & 9.72 \\
Self-Control & 78 & 44.13 & 9.38 \\
Tolerance & 78 & 49.90 & 8.75 \\
Good Impression & 78 & 43.24 & 9.74 \\
Communality & 78 & 54.40 & 5.85 \\
Achievement by Conformance & 78 & 53.26 & 10.13 \\
Achievement by Independence & 78 & 58.05 & 8.30 \\
Intellectual Efticiency & 78 & 51.95 & 9.42 \\
Psychological-Mindedness & 78 & 51.55 & 9.64 \\
Flexibility & 78 & 55.49 & 9.65 \\
Femininity & 78 & 50.73 & 8.60 \\
\hline
\end{tabular}

religiousness has a negative influence, such instances need to be judiciously assessed and differentiated from the more positive kinds of spiritual involvements and commitments, which can be useful assets to the counseling process (Bergin, 1986; Lovinger, 1984; Silverman, 1986; Spero, 1985).

Although the data do not reveal strong relations, the mean scores on the personality measures and the correlations of these measures with the Allport and Ross (1967) ROS provide moderate evidence that religious intrinsicness is positively associated with personal adjustment. The CPI scores are comparable to and, in some cases, more favorable than, those obtained by other investigators on normal populations (e.g., Borden \& Francis, 1978; Gough, 1964, 1975; Mills \& Bohannon, 1980). The same is true for the MAS scores. Hundal,

Table 2

Religious Orientation Scale Means of Brigham Young University Students Compared With Those of Other Samples

\begin{tabular}{|c|c|c|c|}
\hline Sample & $N$ & $I$ & $E$ \\
\hline Present study & 151 & 38.43 & 23.68 \\
\hline Donahue (1981): Purdue University undergraduates & 105 & 28.11 & 28.78 \\
\hline $\begin{array}{l}\text { Hood (1978)" undergraduate psychology students (primarily Baptist and Methodist) } \\
\text { Paloutzian, Jackson, \& Crandall (1978) }\end{array}$ & 147 & 32.00 & 36.00 \\
\hline Introductory psychology students (professing Christians) & 66 & 32.30 & 31.58 \\
\hline Adults (Sunday school and University of Idaho professing Christians) & 147 & 38.06 & 27.53 \\
\hline Boit (1977): undergraduate psychology students (conservative Protestants) & 62 & $36.18^{b}$ & 21.13 \\
\hline $\begin{array}{l}\text { Shoemaker \& Bolt (1977): introductory psychology students (conservative Protes- } \\
\text { tants) } \\
\text { Thompson (1974) }\end{array}$ & 51 & $36.51^{\circ}$ & 21.86 \\
\hline $\begin{array}{l}\text { Catholic parochial high school and Sunday school students } \\
\text { Mothers of these students } \\
\text { Fathers of these students }\end{array}$ & $\begin{array}{l}532 \\
532 \\
532\end{array}$ & $\begin{array}{l}29.50 \\
34.30 \\
28.20\end{array}$ & $\begin{array}{l}36.70 \\
29.30 \\
29.70\end{array}$ \\
\hline Hood (1972) & & & \\
\hline $\begin{array}{l}\text { Introductory psychology students (American Baptist) } \\
\text { Introductory psychology students (Southern Baptist) }\end{array}$ & $\begin{array}{l}34 \\
38 \\
\end{array}$ & $\begin{array}{l}40.06 \\
40.40 \\
\end{array}$ & $\begin{array}{l}47.91 \\
48.06 \\
\end{array}$ \\
\hline
\end{tabular}

- Medians rather than means. ${ }^{b}$ Calculated by reversing the scoring reported in the article. 
Table 4

Means and Standard Deviations on the Irrational Beliefs Test and Beck Depression Inventory (for the Religion Class)

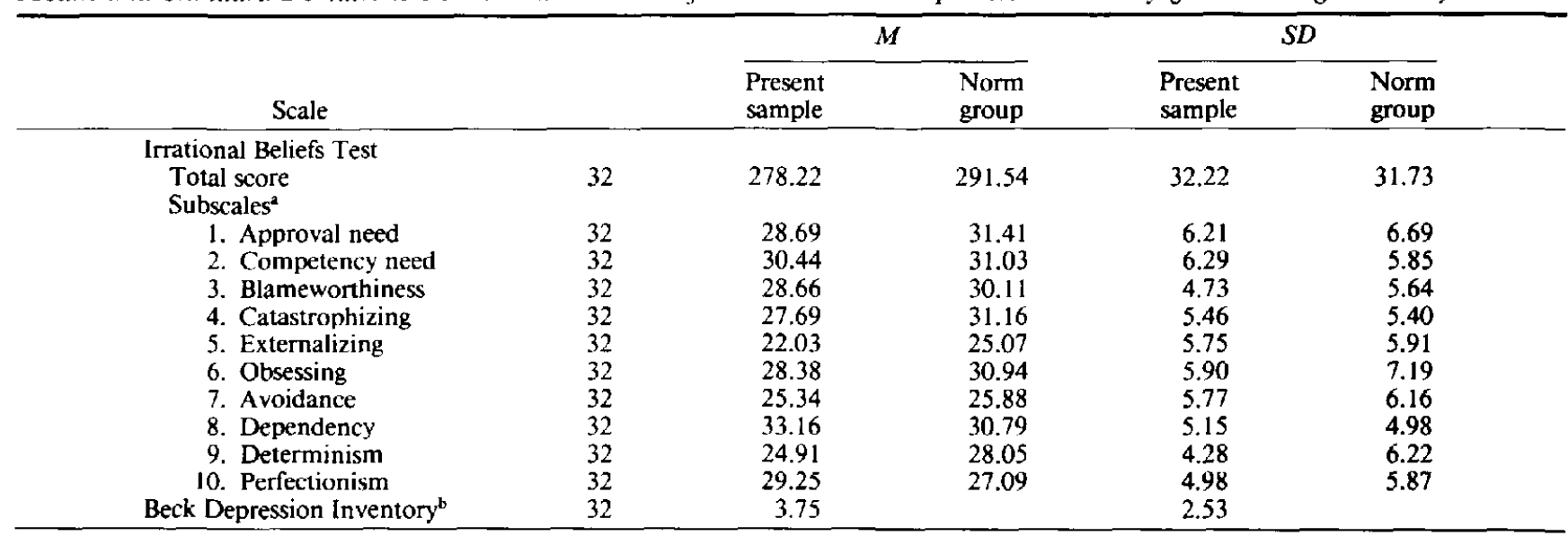

a Names are our abbreviations. ${ }^{b}$ There are no Beck Depression Inventory norms for college students. Means vary from 4.70 to 7.28 , and standard deviations vary from 5.43 to 6.89. (See Lightfoot and Oliver [1985] for data and references.)

Singh, and Singh (1970), Edwards, Cone, and Abbott (1970), and Taylor (1953) reported similar means for their college student samples.

We cannot generalize much, however, because our sample is not necessarily representative of religious people, students in general, or even BYU students. The homogeneity that occurred in our groups of advanced psychology majors and former missionaries provided a good test situation for the intrinsic orientation, but it does not allow for generalizations beyond that, even to the Mormon population. For instance, our preliminary findings from a heterogeneous sample of BYU freshmen yielded a greater range of scores on both $I$ and $E$ than was obtained in the present study.

Our sample also did not permit adequate assessment of negative religiosity, such as clear cases of extrinsic orientations, but it did show that various indexes of emotional distress covaried with extrinsic scores. The significant correlations of the ROS with manifest anxiety are supportive of findings from previous studies (Baker \& Gorsuch, 1982; Bergin, 1983; Sturgeon \& Hamley, 1979).

All these suggest that $I$ is associated with less anxiety, whereas $E$ is associated with more anxiety. As noted by Baker and Gorsuch (1982), these findings clarify the conflicting results of some earlier studies; one study would show a positive correlation between a religion measure and a pathology measure, another study would show exactly the opposite, and still another would reveal no relation. It appears that these studies did not recognize the existence of differing types of religiousness and, therefore, yielded inconclusive findings when they were compared and summarized (Bergin, 1983). Depending on how one defines religion, he or she could produce results indicating that religion is related to either high or low anxiety. The differentiation of religion into $I$ and $E$ orientations, thus, makes more meaningful the conclusions that may be drawn regarding religion and its relation to mental health. This was evident across the many measures we used.

We used two measures of self-control, the SCS and the SelfControl scale of the CPI. Both are concerned with self-regu- lation, freedom from impulsivity, and independence from external environmental cues. The $I$ measure was positively related to self-control on both scales (cf. McClain, 1978) but $E$ was negatively related, although it did not reach statistical significance. This finding again demonstrates the relation between $I$ and a positive personal trait. The ability to control one's impulses and act independently is essential to many areas of healthy functioning. Contemporary coping skills strategies rely heavily on various aspects of self-control, such as the ability of individuals to use cognitive strategies (e.g., selfstatements and problem-solving techniques), delay immediate gratification, and believe that they can regulate their behavior (Rosenbaum, 1980).

Regarding the SCS, the present sample had means somewhat higher than those reported by Rosenbaum (1980). This suggests that higher levels of self-control were present in the sample used in this study, as might be expected by the selective factors established by the university for admitting students. This high degree of control, however, is not associated with anxiety or other indexes of emotional disturbances and is, therefore, contrary to theories suggesting that orthodox religiousness is associated with pathological overcontrol.

The findings on the Sense of Well-Being scale of the CPI replicate those of Alker and Gawin (1978). They used this scale as a measure of happiness, and their conclusion that happiness is more prevalent among psychologically mature (high-I) people is supported by this research. These findings suggest that $I$ is associated with freedom from self-doubt; minimization of worries; and an enterprising, alert disposition, whereas the opposite is true of $E$ (Gough, 1975).

Examination of the Tolerance scale reveals results that support those of Allport and Ross (1967) regarding the relation of religiousness to prejudice. They concluded, "Intrinsically motivated churchgoers are significantly less prejudiced than the extrinsically motivated" (Allport \& Ross, 1967, p. 441). Our results suggest that $I$ is positively related with tolerance and that $E$ is negatively related with it. This finding is of particular importance in the light of the view suggesting 
that religiousness is necessarily associated with judgmental and intolerant social attitudes. The specification of religiousness into $I$ and $E$ reveals that this may be true of only the $E$ orientation.

Other CPI findings suggest that $l$ is positively related to such traits as sociability, responsibility, social maturity, ability to create a favorable impression, and intellectual efficiency. The extrinsic oricntation, on the other hand, is negatively related to sociability, poise and spontaneity, responsibility, tolerance, ability to create a favorable impression, achievement by means of conformance, achievement by means of independence, intellectual efficiency, and the qualities that underlie and lead to status.

The finding in the missionary subsample that $E$ correlated significantly with Scale 5 of the IBT is certainly not surprising given that this scale is indicative of a general orientation toward external, as opposed to internal, causality. A somewhat more interesting finding was the significantly negative relation between $I$ and Scale 9 . This result indicates that $I$ is associated with the acceptance of personal responsibility and with the idea that although the past may influence behavior, it is not an all-powerful determiner of it. Thus, actions taken in the present may have potent remediation effects and, therefore, should be attempted. This finding is also in accordance with the previously mentioned positive relation between $l$ and responsibility as measured on the CPI. Overall, however, contrary to Ellis's hypotheses, this sample showed irrational beliefs and religiousness to be unrelated. This may have been due in part to the restricted range on the ROS, as noted earlier. This was undoubtedly also a factor in the failure to find a relation between ROS and depression, although in this case the depression scores were also very narrow in range.

We were somewhat surprised to find that the missionary group scored so low on both the IBT and the BDI. There may be positive selective factors in who goes on a mission (for 2 years), or the missionary experience is maturing, or both.

Despite the positive support in our data for a certain way of being religious, the possibility that the observed pattern of correlations reflected a social desirability artifact must be considered. For instance, are the responses to $I$ and the other scales laden with social approval response sets, especially given that in this university atmosphere, prosocial behavioral standards and a positive appearance are reinforced? We noted, however, that "good" responses on the IBT do not appear to be easily discernible. The CPI and MAS are subject to response biases. However, our participants were similar to other normative college samples on these scales. It has also been found that the $I$ and $E$ scales do not correlate substantially with social desirability or with "fake-good" scores (Donahue \& Bergin, 1986; Richards, 1985b). We also examined several other sets of data collected on other samples of students at our university. There was no evidence of significant fakegood mean profiles. For instance, Minnesota Multiphasic Personality Inventory findings on several thousand subjects (cf. Bergin et al., in press) revealed no substantial deviations on the $L$ or $K$ scales. On the basis of these observations, we doubt that our findings can be attributed to social approval response sets.
Consequently, we conclude that (a) the $I$ orientation is related to many positive personality traits, but the opposite is true of the $E$ orientation and (b) the sample used, consisting of highly intrinsic subjects, was normal in terms of personal adjustment and mental health so far as this may be estimated by test scores. Other methods of evaluating this question have yielded similar conclusions (Bergin et al., in press). Allport (1968) stated, "I feel equally sure that mental health is facilitated by an intrinsic, but not by an extrinsic, religious orientation" (p. 150). This research offers support for that position, which suggests the need to reconsider the relation between religiousness and mental health in more specific terms and to avoid the kind of misleading overgeneralizations that have caused confusion in this field of inquiry.

\section{Causality in the Religion and Adjustment Equation}

Our findings, like those of most studies in this field, do not reveal causal connections. It could be that intrinsic religiousness facilitates adjustment, that good adjustment facilitates intrinsicness, or that the relation is circular. It is also possible that in devoutly religious families, child-rearing practices are inextricably laced with spiritual variables so that personality development and religiousness are manifestations of a single process. There are so many unknowns in this complex domain that definitive statements are precluded.

\section{Implications for Counseling}

Some useful speculations concerning the counseling situation can be derived from our findings. In the counseling interview, all the complexity we have just alluded to can be seen vividly. Personal religiousness, as measured by Allport and Ross (1967), is indeed related both positively and negatively to other features of personality. All the evidence that we have seen to date indicates that the intrinsic orientation is an asset. When it is discerned in a client, the religious factor can be used therapeutically to provide leverage in favor of growth. Appeals can be made to the positive values that such persons hold to when using cognitive approaches to selfregulation, to the reconstrual of one's position relative to parents, and to life planning (Bergin, 1985a). Other strengths that can be used involve the availability of social support from the religious community and the renewing features of certain religious experiences that have been outlined by Lovinger (1984) and Spero (1985).

On the other hand, defensive or otherwise pathological religious content must be dealt with sensitively and patiently, as with any kind of disturbance in adjustment. The extrinsic orientation, for instance, reflects shallowness and a manipulative style that shows up in both the religious and personality indexes. Also present is a rigidity that makes insight and change more difficult to achieve.

A therapeutic goal may be to help extrinsics become more intrinsic, both religiously and in general, and one would expect to use the intrinsic's assets to stimulate further growth in directions already evident. 
There is a danger, of course, in making value judgments about a client's beliefs or religious affiliation, but we are not advocating that so much as we are the unraveling of religious themes in personal development. When these themes are exposed to the client, the choices that favor better functioning are frequently obvious; in any case, these choices have to bc up to the client. Although both counselor and client values operate in the change process, the highest value favors client autonomy (Bergin, 1985a) because without autonomy and the responsibility to face the consequences of choices, growth is impossible.

\section{References}

Alker, H. A.. \& Gawin, F. (1978). On the intrapsychic specificity of happiness. Journal of Personality, 46, 311-322.

Allport, G. W. (1968). The person in psychology selected essays. Boston: Beacon.

Allport, G. W., \& Ross, J. M. (1967). Personal religious orientation and prejudice. Journal of Personality and Social Psychology, 5, 432-443.

Baker, M., \& Gorsuch, R. (1982). Trait anxiety and intrinsic-extrinsic religiousness. Journal for the Scientific Study of Religion, 21, 119122.

Bergin, A. E. (1980a). Psychotherapy and religious values. Journal of Consulting and Clinical Psychology, 48, 95-105.

Bergin, A. E. (1980b). Religious and humanistic values: A reply to Ellis and Walls. Journal of Consulting and Clinical Psychology, 48, 642-645.

Bergin, A. E. (1983). Religiosity and mental health: A critical reevaluation and meta-analysis. Professional Psychology: Research and Practice, 14, 170-184.

Bergin, A. E. (1985a). Proposed values for guiding and evaluating counseling and psychotherapy. Counseling and Values, 29, 99116.

Bergin, A. E. (1985b). Values in personality change and positive growth: A response to commentaries by Gazda and Sprinthall. Counseling and Values, 30, 87-89.

Bergin, A. E. (1986). Psychotherapy and religious factors [Review of Working with religious issues in therapy and of Psychotherapy of the religious patient]. Contemporary Psychology, 31, 85-87.

Bergin, A. E. (in press). Three contributions of a spiritual perspective to psychotherapy and behavior change. Counseling and Values.

Bergin, A. E., Stinchfield, R. D., Gaskin, T., Masters, K. S., \& Sullivan, C. E. (in press). Religious lifestyles and mental health: An exploratory study. Journal of Counseling Psychology.

Bolt, M. (1977). Religious orientation and death fears. Review of Religious Research, 19, 73-76.

Borden', R. J., \& Francis, I. L. (1978). Who cares about ecology? Personality and sex differences in environmental concern. Journal of Personality, 46, 190-203.

Donahue, M. J. (1981). What is religiosity? A logical learning analysis. Unpublished doctoral dissertation, Purdue University, West Lafayette, IN.

Donahue, M. J. (1985). Intrinsic and extrinsic religiousness: Review and meta-analysis. Journal of Personality and Social Psychology, $48,400-419$.

Donahue, M. J., \& Bergin, A. E. (1986). Religion, personality, and lifestyle: Review and meta-analyses. Manuscript submitted for publication.

Edwards, A. L. Cone, J. D., \& Abbott. R. D. (1970). Anxiety, structure, or social desirability. Journal of Consulting and Clinical Psychology, 34, 236-238.

Ellis, A. (1980). Psychotherapy and atheistic values: A response to A. E. Bergin's "Psychotherapy and religious values." Journal of Consulting and Clinical Psychology, 48, 635-639.

Gazda, G. M. (1985). A response to Bergin's "Proposed values for guiding and evaluating counseling and psychotherapy." Counseling and Values, 30, 86-87.

Gough, H. G. (1964). Academic achievement in high school as predicted from the California Psychological Inventory. Journal of Educational Psychology, 55, 174-180.

Gough, H. G. (1975). Manual for the California Psychological Inventory (Rev. ed.). Palo Alto, CA: Consulting Psychologists Press.

Hood, R. W., Jr. (1972). Normative and motivational determinants of reported religious experience in two Baptist samples. Review of Religious Research, 13, 192-196.

Hood, R. W., Jr. (1978). The usefulness of indiscriminately pro and anti categories of religious orientation. Journal for the Scientific Study of Religion, 17, 419-431.

Hundal, P. S., Singh, A., \& Singh, M. (1970). Factor analytical study of tests of anxiety. Psychological Reports, 26, 875-878.

Jensen, J. P. (1986). Mental health values of professional therapists: A national interdisciplinary survey. Unpublished doctoral dissertation, Brigham Young University, Provo, Utah.

Jones, R. G. (1977). Jones's irrational beliefs handbook. Wichita, KS: Test Systems International

Kahoe, R. D. (1974). Personality and achievement correlates of intrinsic and extrinsic religious orientation. Journal of Personality and Social Psychology, 29, 812-818.

Lightfoot, S. L., \& Oliver, J. M. (1985). The Beck inventory: Psychometric properties in college students. Journal of Personality Assessment, 49, 434-436.

Lovinger, R. J. (1984). Working with religious issues in therapy. New York: Jason Aronson.

McClain, E. W. (1978). Personality differences between intrinsically religious and nonreligious students: A factor analytic study. Journal of Personality Assessment, 42, 159-166.

Mills, C. J., \& Bohannon, W. E. (1980). Personality characteristics of effective state police officers. Joumal of Applied Psychology, 65, 680-684.

Paloutzian, R. F., Jackson, S. L., \& Crandall, J, E. (1978). Conversion experience, belief system, and personal and ethical attitudes. Journal of Psychology and Theology, 6, 266-275.

Redden, E. M., Tucker, R. K., \& Young, L. (1983). Psychometric properties of the Rosenbaum Schedule for Assessing Self-Control. Psychological Record, 33, 77-86.

Richards, P. S. (1985a). Construct validation of the Self-Control Schedule. Journal of Research in Personality, 19, 208-218.

Richards, P. S. (1985b). [Social desirability and religious orientation scores]. Unpublished raw data, Department of Counseling and Student Personnel Psychology, University of Minnesota, Minneapolis.

Rosenbaum, M. (1980). A schedule for assessing self-control behaviors: Preliminary findings. Behavior Therapy, 11, 109-121.

Shoemaker, A., \& Bolt, M. (1977). The Rokeach Value Survey and perceived Christian values. Journal of Psychology and Theology, 5, $139-142$.

Silverman, H. L. (1986). Psychotherapy and religious factors [Review of Working with religious issues in therapy and of Psychotherapy of the religious patient]. Contemporary Psychology, 31, 87-88.

Spero, M. H. (Ed.). (1985). Psychotherapy of the religious patient. Springfield, IL: Charles C Thomas.

Sprinthall, N. A. (1985). Proposing values: The right question but the 
wrong epistemology-an invited response to Bergin. Counseling and Volues.

Sturgeon, R. S., \& Hamley, R. W, (1979). Religiosity and anxiety, Journal of Social Psychology, 108, 137-138.

Taylor, J. A. (1953). A personality scale of manifest anxiety. Journal of Abnormal and Social Psychology, 48, 285-290.

Thompson, A. D. (1974). Open-mindedness and indiscriminatory antireligious orientation. Joumal for the Scientific Study of Reli- gion, $13,471-477$.

Walls, G. B. (1980). Values and psychotherapy: A comment on "Psychotherapy and religious values." Journal of Consulting and Clinical Psychology, 48, 640-641.

Received April 30, 1986

Revision received July 28,1986 